\title{
Do Mature Industries Have their Own Innovation Dynamics? A Reflection Based on the Development of the Thermoplastic Vulcanizates Industry
}

Currently, studies into the dynamics of technological innovation seem to pay more attention to new sectors capable of bringing about great social and economic change, like biotechnology and information technology, and leave aside those sectors which could be called mature, and which are seen as generating little in terms of innovation. This study investigates the creation of the thermoplastic vulcanizates industry as an example of innovation constructed within a mature industry, in this case, the petrochemicals industry. A characterization is made of this innovation process, identifying the technological and organizational dimensions that are inherent to it as well as the nature of the competencies and resources mobilized by the companies involved in the innovation. The study involves an analysis of both the development of patents concerning the production and use of this material and its market developments in terms of volume, producers and applications. Introduced into the market at the beginning of the 1980s, this product involves a segment of an industry which is considered to have reached its mature stage. The sector study identified data on volumes, market segments involved, main players and the competitive forces at play in the market. The survey of patents filed between 1980 and 2000 provided a basis for identifying how the following factors have changed with time: process, product and application patents; the segments in which TPVs are applied; and the types of companies filing the patents. The findings of this study include the importance of application innovations, placement strategies for new products and even the strategy of market entrants. It is hoped that these findings and the methodology employed may be used as a basis for building up a model for innovation dynamics in mature industries.

Technological innovation is of increasing importance to countries and businesses, providing as it does an essential competitive edge in the markets of today, not to mention the markets of the future. In such an environment, the attention of those who study innovation is drawn to the dynamics of those sectors of the economy which bring about novelties of impact to industry and society. In recent years, attentions have clearly turned to information technology and biotechnology.

However, if this process of innovation is inherent to current economic activities, one may ask how it is manifested in more mature industries whose golden age was in the mid 20th century. One such sector is synthetic materials - plastics, elastomers and fibers - which were in great demand in the post war years, and which have underpinned the innovation dynamics of the chemicals industry for some decades. What is the significance of innovation to these sectors? How is it organized? To what extent can existing concepts explain the innovation dynamics in these so-called mature industries? What this study does is to make an initial investigation into these issues by studying the emergence and dissemination of one innovation from the polymers segment, involving plastics and elastomers or synthetic rubbers.

Normally, researchers interested in this area and the literature they produce consider two types of innovation: process and product. While these types of innovation can account for what happens in the newest, most dynamic industries, it seems that they fail to do so when it comes to some key aspects of the innovation dynamics in more mature industries. With a shorter life cycle for products, the convergence of technologies, and the increasing difficulty to identify real "boundaries" in different production chains, producers and clients are coming into increasingly closer contact. Producers have started needing to acquire knowledge about their clients' businesses if they want a competitive edge in the marketplace and if they are to prepare for potential changes to it. And it is here that there is a need to introduce a new concept for producers' innovations: application innovation. Producers need to innovate within their clients' own area.

With the aim of providing some guidelines for those people in charge of technological innovation in companies, this study seeks to identify the relationships between the three types of innovation, how they change with time, and their influence on the life cycle of products and the market itself. It also seeks to identify the innovation dynamics of a mature industry by analyzing the development of an innovation that is located at the interface between two industries: plastics and rubber. To this end, an analysis is made of how innovations involving thermoplastic vulcanizates (TPVs) and the TPV market have changed with time.

The paper is presented in six sections. The second section contains a literature review of different types of innovation and the concepts behind them. It also contains 
an analysis of how process and product innovation rates vary as industries develop. The third section takes innovation and applies it to some examples obtained from the market. The fourth presents the thermoplastic vulcanizates market. The fifth section covers the methodology adopted and the findings of the study. The final section contains some conclusions and puts forward the final recommendations of this work.

\section{Types of innovation and how they change throughout an industry's lifecycle}

In a study published in 1991 by the OECD, technological innovation is defined as an interactive process triggered by the perception of an opportunity in a new market or service. This perception leads to the deployment of development, production and marketing efforts to assure a given invention's commercial success. Thus, innovation does not just cover basic and applied research, but also includes product development, production, marketing, distribution and even product adaptations and improvements.

This somewhat interactive nature of innovation means that the concept of continuous improvement can be developed, which in turn means that different types of innovation can be identified (Garcia \& Calantone, 2002). These include radical innovations, which change the behaviors in and structure of a given market, and which are associated with original products / processes in their initial stages of adoption and diffusion, as well as incremental innovations, which are small improvements to processes and/ or products made on a base that is already in place. However, even though incremental innovations do not alter a market's structure or behavior, they may of themselves be radical innovations from the viewpoint of a business that adopts them, in that they may involve the incorporation of a new technology base.

Innovations or processes of technological change can also be classified according to whether they affect a process or a product. Narayanan (2001) sees good reason for making such a distinction:

- product innovations are more easily picked up by the market than process innovations. The latter are harder for clients or competitors to identify. They are therefore easier to protect from copying by the competition;

- they have different implications for businesses. Product innovations give an edge in competition for customers and even in redefining a product's / market's scope.. Process innovations bring about production cost savings and enhance productivity and product quality. Changes to processes can even alter how a business operates. Such innovations can bring about organizational changes, including altered practices involving human resources, logistics and marketing functions.

Narayanan (2001) defines process innovations as those related to production techniques and marketing. They include changes to methods, equipment, distribution and logistics. Meanwhile, product innovations are related to the technological features incorporated into a business's goods and services. These changes may range from a simple refinement to a totally new product.

The Oslo Manual (OECD, 1992), which is designed to standardize concepts and put forward methodologies for data collection concerning innovations, views innovation as no more than the introduction of a new product or a new production method (process). It states that process innovations include the implementation/adoption of novel or significantly improved production or distribution methods. This may involve changes to equipment, human resources, working methods or a combination thereof. Likewise, it defines product innovations as those that involve the implementation/sale of a product with improved performance characteristics capable of bringing about new or improved services for customers.

In Utterback's (1994) view, a technology's or industry's lifecycle comprises three development phases: fluid, transitional and specific. Following table shows some of the characteristics by which each of these phases can be identified.

In the fluid phase, there is great uncertainty as to a company's product, process, competitive leadership and management structure. The product is not clearly defined and it has a high pace of innovation. Products may be produced to order and process innovation takes a supporting role. The processes are flexible, inefficient and based on specialized labor and general-purpose equipment. The companies set up have an organic structure which undergoes frequent adjustments and in which tasks and duties can be re-defined, with a flat hierarchy and a high degree of lateral communication. The market is not yet established; it is fragmented, unstable and provides rapid feedback. A product's functional performance is the basis for competition. There are few competitors but this number grows as the technology penetrates the market. The tendency is for there to be a large number of small businesses set up with original, unique products.

When a dominant product design emerges, this heralds the beginning of the transitional phase. Product innovation rates drop while process innovations rise. Product and process innovations start to be interdependent. Processes become more rigid, specialized equipment is introduced and automation starts to come in. The cost of change starts to rise. Companies start to be less organic and the relative power of people with managerial skills grows. Products tend to start to have commodity-like behavior and the degree of differentiation in terms of their functions or characteristics falls. There are fewer competitors and the basis for competition starts to reside in refinements to product features, reliability and cost. As Utterback (1994) sees it, assembled and non-assembled products have some behavioral differences at this phase. Unlike the former, non-assembled products do not leave the fluid phase when one product design becomes dominant, but rather when a base process technology comes in.

In the specific phase, an industry has entered its maturity phase and the value of the quality / cost ratio becomes the basis for competition. Innovations to the product are 
Table 1. Specific characteristics of each phase of the industrial innovation cycle

\begin{tabular}{|c|c|c|c|}
\hline & Fluid / Emerging Phase & Growth / Transitional Phase & Maturity / Specific Phase \\
\hline Innovation & Frequent changes to the product & Great changes to the process & $\begin{array}{l}\text { Incremental innovation in the product } \\
\text { and cumulative improvements to } \\
\text { productivity and quality }\end{array}$ \\
\hline Products & $\begin{array}{l}\text { Variety of designs for specific } \\
\text { clients }\end{array}$ & $\begin{array}{l}\text { At least one design to generate } \\
\text { a significant volume }\end{array}$ & $\begin{array}{l}\text { Mostly standard, undifferentiated } \\
\text { products }\end{array}$ \\
\hline Production Process & Flexible and inefficient & Increasingly inflexible & $\begin{array}{l}\text { Efficient, capital intensive and rigid; } \\
\text { high cost of change }\end{array}$ \\
\hline $\mathrm{R} \& \mathrm{D}$ & No specific focus & $\begin{array}{l}\text { Focus on specific features of } \\
\text { the project }\end{array}$ & $\begin{array}{l}\text { Focus on incremental technologies } \\
\text { for the product; emphasis on process } \\
\text { technology }\end{array}$ \\
\hline
\end{tabular}

Source: Utterback (1994)

incremental, while improvements to quality and productivity are cumulative. Any modification to either process or product is both difficult and costly. Processes are automated and generally make use of specialized equipment. The organizational structure is based upon clearly defined tasks and procedures. There are few companies, producing standardized or slightly differentiated products, or commodities, which enjoy stable sales and market shares (oligopolies). The pace of innovation, whether for the process or the product, tends towards zero.

\section{Application Innovation}

Nowadays, companies have to strive to achieve an ever closer relationship with their clients, and even with their clients' clients. This means knowing how they use their products and what for; i.e. knowing the "businesses" of the chain that they are part of. This is a dimension that receives little attention in the existing definitions of product innovation that are more restricted. In this paper, the concept of use or application innovations is introduced, which seems pertinent for understanding the innovation dynamics of mature industries. Application innovations involve creating new markets and opportunities and may or may not involve direct alterations to products and processes. Examples of this are the constant discoveries of new applications for plastics, and even the very competition between them, in which case the agent for change or the origin of the innovation is often the machinery used to prepare the artifacts. The role of applications in innovation dynamics can also be illustrated by industries other than the polymer industry. One example is the discovery and use of the laser and microwaves, whose applications today are a far cry from those dreamt up when they were first developed. The dynamics of application innovations also involve the strategic use of a given technology base, multiplying the same technology out into different branches of applications, as is done explicitly by companies like $3 \mathrm{M}$.

The notion of application innovation is coherent with Kline \& Rosemberg's (1986) argument in their classic article on the limitations of the linear innovation model. Innovations often bring about benefits to industries or sectors that are quite removed from those to which they were first introduced. The authors see this as the reason why it is difficult to map out the costs and benefits of many innovations within a single industrial classification structure. They cite the clothing industry as an example, which at the time was making use of many innovations derived from electronic, laser and chemistry technologies.

When a product is developed and put on the market, it is sometimes only successful when it is applied in an unexpected way. This is the case of Surlyn $\AA$, a polyester resin developed by DuPont in the 1960s (Miller, J., 1998). It was initially earmarked for use only in the footwear industry. However, such were its characteristics that the company decided to build a commercial factory to produce it while it set about finding new types of clients and applications. And these new applications took some time to come up. It was only after a concerted development and marketing effort that DuPont effectively managed to place the product on the market. As Miller (1998) himself puts it: “... gradually, the versatile plastic found one new application after another. Today, along with metal films, it packages dog food, medicines and chocolate bars, coats parachutes, skis and surfboards". Even if each of these new applications has meant that some small modification has had to be made to the product or process, it has been the development of new applications, rather than these modifications, that has assured the success of the DuPont project.

Sometimes, a product gains a new breath of life. One case in point is the Japanese company Zeon and its product, Hydrin ${ }^{\circledR}$ (Meyer; 2003). This is an eipchlorohydrin rubber whose market had practically stagnated for ten years. It is normally used in the auto industry because of its high resistance to oil, heat and fuel. In recent years, Zeon has invested in new uses based on some of its properties that have not yet been commercially exploited. The company claims the product is has low gas permeability, dissipates static electricity well and can be blended to formulate products with a wide range of modulus, tensile strength and thermal conductivity. This led to new applications in the auto, manufacturing, electronics and electrical goods industries.

3M's thousands of products are based on a few well 
defined technology bases from which the applications are developed. Their microreplication technology has been used to produce glass overhead projectors lenses, computer screens, microstructured abrasives, reflective road signs, mechanical fasteners for diapers and ID badges; in other words, a totally diverse range of applications (Coyne, 1998).

To sum up, researchers from the area understand technological innovation to be: a new product; a new production process; the production of a given product using cheaper materials; efficiency gains through the reorganization of production, internal functions or distribution bringing about either improved productivity or cost reductions; or an improvement to the instruments or methods used in the innovation process. What the present study does is to propose that the development of new product applications be included in this list. It would seem that this new concept may help ensure a better understanding of the innovation process in some industries.

According to the Utterbach (1994) model, the industrial innovation lifecycle can be reproduced through a new wave of innovations. However, the definition of application innovations may beg a new question: is this new wave related to radically novel innovations which revitalize related processes and products, or is it related to the development of uses of technologies / processes / products in other applications? Below, we investigate the development of the thermoplastic vulcanizates industry, which is behind the renewal of a mature industry thanks to new applications based on established products.

\section{Thermoplastic Vulcanizates}

TPVs normally consist of the mixing and processing of a thermoplastic and a rubber. The rubber may be vulcanized or chemically modified before or while it is mixed with the thermoplastic. The most common production process used is dynamic vulcanization. The components are submitted to a process of intimate melt mixing. High shear rates melt the polymers and disperse the rubber particles in a continuous thermoplastic phase. The extent to which the elastomer is vulcanized and the final properties of the TPV are dependent upon the quantity of curing agent used as well as the process temperature and time. Vulcanization or chemical modification increases the tensile strength and tear strength, reduces the compression set and improves resistance to oils. TPVs have physical properties that allow them to be injection molded, blow molded and extruded.

The great advantage of these elastomers is that they allow "rubbery" artifacts to be manufactured using rapid processing techniques developed by the thermoplastics industry, while allowing for the recycling of the used material or article when they are disposed of.

TPVs were introduced to the US market at the beginning of the 1980s. The table below shows the consumption of the product over the years. Prices range between US\$3.0 and US\$5.0 per kilo. The industry is currently worth some US\$600 million.
As already explained, these materials occupy an interface between the plastics and elastomers industries. As they have found new markets, they have gradually taken on applications originally supplied by products derived from these two industries. Interestingly, this segment cannot be considered a new industry. It uses the industrial base of an existing industry (plastics) and involves companies that operate in the production chains of both industries cited above.

It can be seen from next table that the estimated world demand for TPVs will grow at around 7.0\% p.a. until 2007.

The fact that they have good physical toughness, good elasticity, recyclability, good resistance to oils and other chemicals, good UV resistance, and are paintable, is the key to the increasing preference for these substances over and above other materials like rubbers, metals and plastics in the auto and manufacturing industries. And the high approval rate of TPVs in the sports materials segment is down to their moldability over other polymers.

The industry contains different types of TPV suppliers, which can be split into three levels. The first level includes AES, DSM, Solvay, Zeon, JSR and Toyobo. These are companies originally from the chemicals or polymers industry which have the skills required to develop blends and vulcanizates and to carry out polymerization, to produce raw materials or base polymers. The second level can be seen as intermediate. It includes competitors which are not polymer producers, but which have sufficient knowledge of the materials to be able to develop their own materials. These companies cannot be regarded as compounders, even if they do carry out this activity to some extent. They include Ferro, Polyone and TeknorApex. The third level of suppliers is the compounders. They are normally far smaller than the first and second level companies. They are not involved in polymerization, nor do they have the capacity to develop new materials. As a rule, their materials are developed with the technological support of a first level company with which they form a partnership to obtain technology and exploit market niches.

The TPV industry is going through a flurry of activity with the entry of key players such as Zeon and Solvay. The sector is growing quickly through the establishment of strategic alliances. Some of these are horizontal, between

Table 2. Demand for TPVs (1000 t)

\begin{tabular}{cccccc}
\hline Year & USA & Europe & Japan & Other & $\begin{array}{c}\text { Total Known / } \\
\text { Projected }\end{array}$ \\
\hline 1986 & 13 & ND & ND & ND & 13 \\
1991 & 24 & 16 & 6 & ND & 46 \\
1994 & 34 & 18 & 11 & ND & 63 \\
1998 & 70 & 22 & 16 & ND & 108 \\
2002 & 95 & 27 & 32 & 15 & 169 \\
2007 & 133 & 41 & 45 & 22 & 241 \\
\hline Source : Petroflex (2004)
\end{tabular}




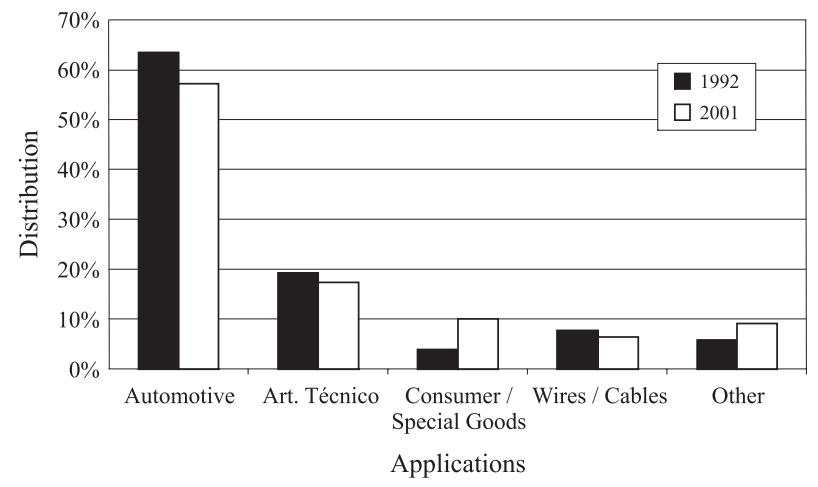

Figure 1. Changes to the consumptions of TPV's as a percentage per segment of application.

companies at the same place in the production chain. Their most common driving factors are a quest for technology (Zeon and AES), the setting up of joint ventures to exploit a business opportunity (Monsanto and Exxon, establishing AES) and geographical expansion (partnerships between AES and DSM with compounders in Asia and other regions, or the sales and marketing partnership between DSM and Toyobo for SARLINK in Japan).

The most important market for TPVs is the auto industry, which accounts for around $50 \%$ of its consumption. The product is also used in sports materials, manufactured goods, wires and cables, etc. The changes in demand for each application of these thermoplastics is shown in Figure 1. The largest of these - the automobile industry - is also the most demanding, given the leading role of car manufacturers in the chain. Meanwhile, the other markets should not be seen as homogeneous, but rather as a set of many individual niches.

Bomtempo \& Cardoso (2004) see the development of applications for TPVs as pivotal to their entry into so many different markets. While the industry's first steps in the 1980s and beginning of the 1990s involved the substitution of rubber, once the simplest material substitutions had been identified and made, the industry turned increasingly to the development of new uses and the substitution of plastics and rubbers.

An analysis of the current state of the segment shows that although it has one foot in each of two mature industries, it is at the beginning of the transitional phase of its own lifecycle. The technological base is available (since the expiration of AES's SANTOPRENE patents), production processes are starting to be automated, the number of participants is on the up / being consolidated, competition is based on product variations and adaptations according to use (application), R\&D is focused on the product and its applications and the cost of change is still moderate.

\section{Methodology}

This study seeks to analyze TPV-related patents to identify the relationships that exist between the three types of innovation, how they have changed with time and how they influence the products' lifecycles and the market itself. A search was made of patents in the American USPTO database using the website www.uspto.gov. The idea was to identify patents involving thermoplastic elastomers filed between 1980 and 2000. The search was carried out using keywords in the titles and abstracts of the patent documents. The terms searched for were: process thermoplastic elastomers; product blends; and the terms, energy, automotive, cables, tools, hoses, tubes, coatings and filaments for applications.

From this search, 922 patents were selected for analysis, excluding repetitions, and these formed the patent database initially set up for this study. This led to the identification of 187 patents concerning TPVs per se. Through an analysis of the claims, the patents were further classified according to the type of innovation developed (process, product and application) and the application it was intended for (when applicable). In view of the fact that more than one type of application was claimed per patent filed, the patents were then classified as: process, process/application, process/ product, process/product/application, application, and application/product.

\section{Results}

Figure 2 shows the number of TPV-related patents identified during the period in question. The growth observed is in line with the increased sales of the product and growing number of producers entering this market, especially as of the second half of the 1990s, when the main Monsanto/AES patents for Santoprene were expiring (Bomtempo \& Cardoso, 2004).

Figure 3 shows the total distribution of TPV-related patents per type of innovation and Figure 4 shows their changes with time.

Growth in application-related patents can be seen. This seems to support the declarations made and actions taken by companies operating in the sector, and one could say that currently the development of applications is the TPV industry's focal point. The first concern was to file process and product patents, which would assure a strong initial market position. Then, differentiation was sought and new service-based entrants even joined the market. In technological terms, this has meant working on the materials'

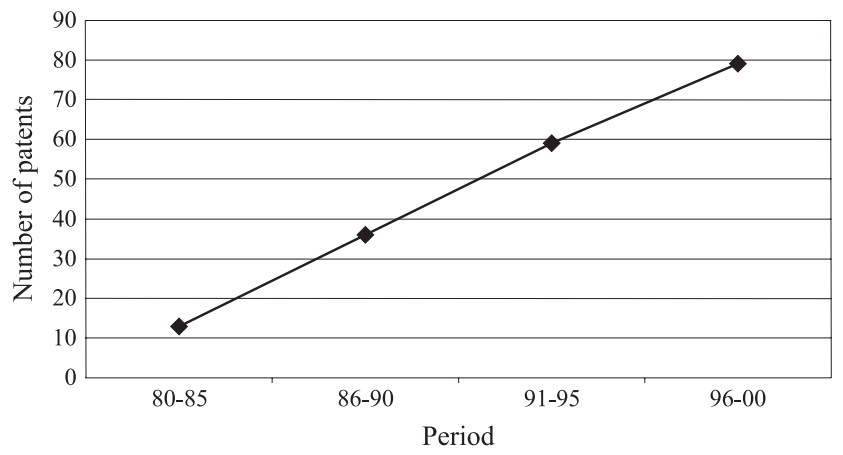

Figure 2. Number of TPV patents. 


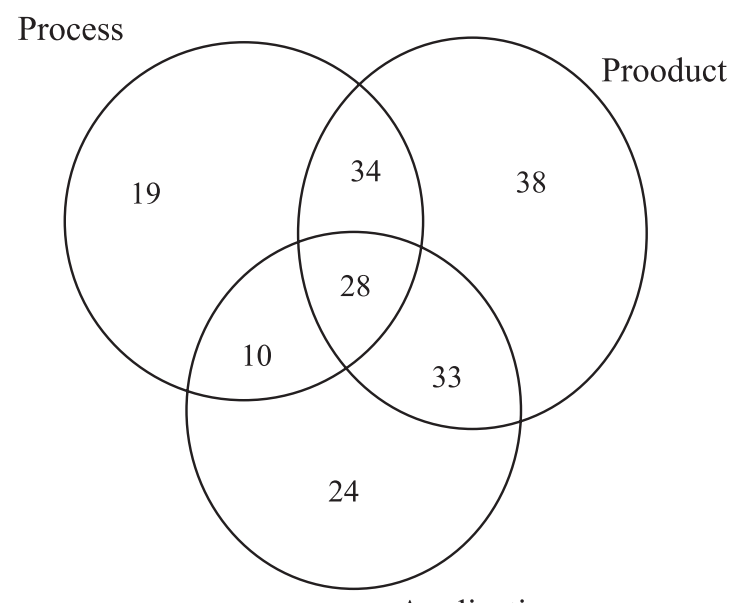

Application

Figure 3. Distribution of TPV patents per application.

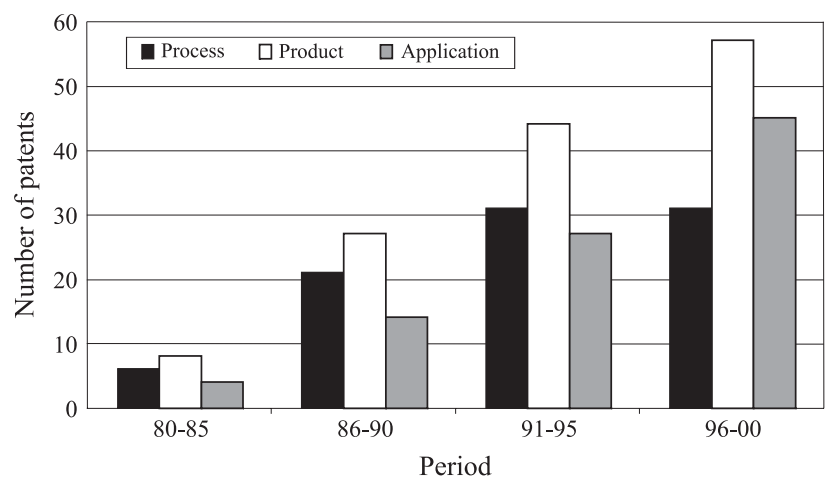

Figure 4. Types of TPV innovations.

characteristics in two senses. The first responds to potential uses of the material identified through observations of markets and their current and/or future needs; in other words, "market pull". This is where attempts to replace rubber or PVC for TPVs have comes in, for instance. Meanwhile, on the other side, TPV suppliers have sought to expand the range of their products' properties so as to open up new application opportunities under conditions which previously prevented their use because of some shortfall in the materials themselves. This is the "technology push side of the equation.

Figure 5 shows how the number of innovations has changed during each of the periods analyzed. It was assumed that this variation represents the pace of innovation, or innovation rate. The idea was to match the findings obtained here against classic product and process innovation curves from Utterback's model. It should not be forgotten, however, that Utterback focuses on the early stages of industry development, while the TPV industry is part of a larger industry, that of plastics and rubber, which could be regarded as mature.

Figure 6 changes to application-related patents per market, seems to be in line with what one could expect for market entry. First, companies focus on a higher volume segment, where quality and performance requirements are an overriding factor for a product's success. Once a product is validated in this segment, they then seek greater diversification. The increased number of patents is in line with the idea that companies would be seeking out niches other than the auto industry to sell their product. This is also coherent with the data presented in Figure 1, which shows a drop off (albeit reduced) in the percentage of sales to the auto industry.

This study also sought to investigate how the number of patents has changed per type of patent filer. The intention is to identify the players involved in innovation in the chain, according to von Hippel's (1988) proposal, which considers the possibility of functionally different players being dynamic agents of a given innovation. The patent filers were classified into five groups: suppliers, type 1 producers, type 2 produces, users and independent. Suppliers are the producers of polymers who simply seek a position in the TPV market by supplying raw materials. They therefore benefit from innovations through the increased sale of raw materials. Type 1 producers are TPV producers that are integrated with the production of the raw materials, elastomers or plastics used in its composition. They also include those producers which have a shareholding interest in raw materials producers. Type 2 producers are known as compounders; they use their knowledge of plastic and rubber processing and their relationships with users to enter the TPV market. Users are companies that incorporate TPV into the products they sell. Independents are the other players, such as public authorities, individuals and universities, which have

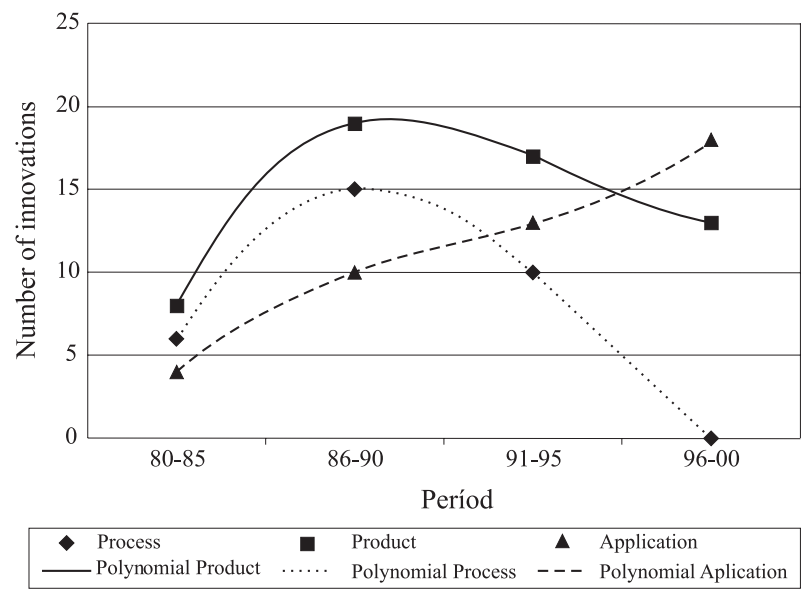

Figure 5. Pace of innovation per type of innovation

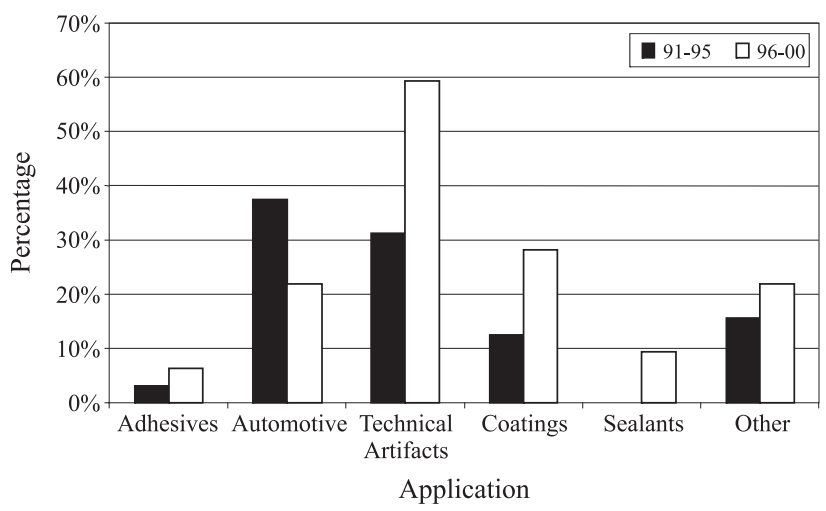

Figure 6. Percentage of TPV patents per type of application. 


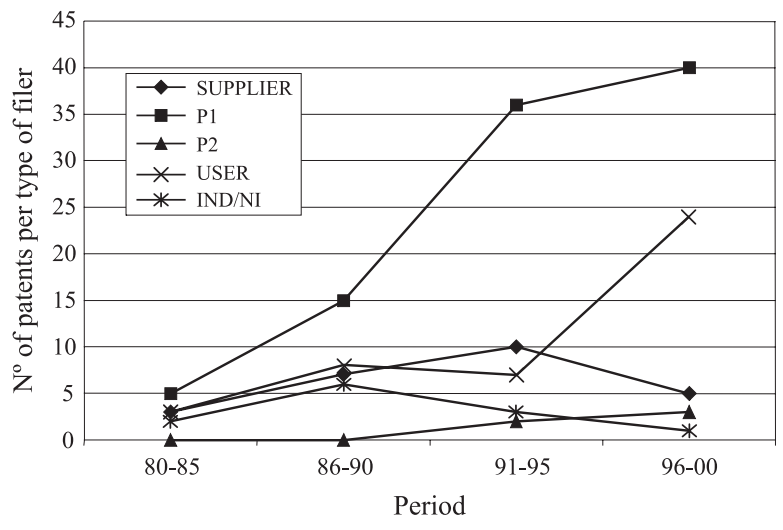

Figure 7. Types of TPV patent filers

no direct relation with the business itself except for the technology developed for it.

Figure 7 shows the number of patents per type of patent filer. During all the periods in question, there is always a higher number of type 1 producers. However, the number of users entering the field in question is growing noticeably, which indicates the acceptance of the product in their businesses. Type 2 producers start to come into their own in the second half of the 1990s. One can assume that as the study only searched for patents filed up to 2000, it was not possible by then to assess the impact of the entry of these companies on the production of TPVs, since this only happened as of the end of the 1990s. There is also an interesting growth in patents filed by product users. The consolidation of TPVs in the market, product enhancements in terms of their processability (ease of use by customers), and an expanding range of applications may account for the growing interest of these users, which are interested in the differential these elastomers can bring their businesses.

Actually, it would not be far fetched to say that TPV producers may be less inclined to file application-related patents. In theory, they should be primarily concerned with preserving their business and consequently protecting their processes and products. One might therefore say that numerous application innovations have not been protected by patent. As time goes by and the product is accepted by the market, however, users start to show interest in working with the product and thereon in to protect its developments through patenting.

\section{Considerations}

This analysis of the changes to patenting in the area has helped to identify how innovation has developed in the TPV segment. The importance of application innovations has been seen, as has the way they have been used to achieve product consolidation in the market. Likewise, the market analysis shows that in the first years of TPV production and during its changes in the 1990s, there was a clear effort to move away from a product-centered working style towards an applicationcentered approach. Since then, both AES and its followers have organized their sales according to the end market.
Santoprene has always been seen as a product with promising characteristics, but it only took off after a special effort was made that focused on its uses, which led to the identification and development of key applications. The findings of this study could help inform decision taking by companies considering entering the sector and even serve as a guideline for the work of R\&D managers responsible for developments in the area, reducing the risks inherent to the activity by identifying where, how and when to invest.

This study also provides a blueprint for other analyses into the innovation dynamics of mature industries. The introduction of TPVs was an innovation which marked the start of a new cycle. The period analyzed could be understood as the fluid and transitional phases from the Utterbach (1994) model. The first innovations focus on process and product. As far as applications are concerned, a market is initially sought out that is capable of absorbing the innovations, in terms of volume, quality requirements, variability and continuous improvement (as is the case of the auto industry). After consolidation, the number of producers starts to rise (which may even involve links from the initial chain compounders) and applications start to be diversified. The TPV industry has now reached this stage. One may infer that in the not too distant future, attentions may well return to the process in response to the fiercer competition liable to be caused by the high number of new entrants at the moment.

Nonetheless, we recognize that this is not a comprehensive assessment and that one cannot generalize from one single study. It would therefore be of interest for studies of other mature industries to be carried out using this methodology to discover if the findings presented in this work are supported or contested.

\section{References}

Bomtempo, J. V. \& Cardoso, L. - "Análise Competitiva da indústria de elastômeros termoplásticos", study developed for Petroflex, 2004.

Coutinho, P. L. - "Estratégia Tecnológica e Gestão da Inovação: uma Estrutura Analítica voltada para os Administradores das Empresas", Doctoral Thesis, Escola de Química, Universidade Federal do Rio de Janeiro, Jan., 2004.

Coyne, W. E. - "3M Minnesota Mining and Manufacturing Company”, In: Kanter, R. M., Kao, J., Wiersema, F., Inovação, Negócio Editora Ltda, São Paulo, SP, p. 64, 1998.

Garcia, R. \& Calantone, R., "A critical look at technological innovation typology and innovativeness terminology: a literature review", The Journal of Product Innovation Management, 19, p. 110-132, 2002.

Hippel, E. - The sources of Innovation, Oxford University Press, New York, 1988.

Kline, S. \& Rosemberg, N., “An Overview of Innovation”, In: 
, Landau, R. \& Rosemberg, N., The Positive Sum Strategy, National Academy Press, Washington D.C., 1986.

Merrifield D. B. - "Value-added: the dominant factor in industrial competitiveness", Special Publication on the Role of Technology In: Corporate Policy, p. 226-235, 1991, Apud Berry, M. M. J., Taggart, J. H., "Managing Technology and innovation: a review", $R \& D$ Management, 24, 4, p. 341-353, 1994.

Meyer, B. - "Zeon trying to pump new life into Hydrin", Rubber \& Plastics News, December, p. 10, 2003.

Miller, J. - "E. I. DuPont de Nemours and Company, Inc" In: Kanter, R. M., Kao, J., Wiersema, F., Inovação, Negócio Editora Ltda, São Paulo, SP-Brazil, p. 84, 1998.

Narayanan, V. K. - Managing technology and innovation for competitive advantage, Prentice Hall Inc, New Jersey, USA, 2001.
OECD - The nature of innovation and the evolution of the productive system. Technology and productivity- the challenge for economic policy, Paris: OECD, 1991, p. 303-14, Apud GARCIA, R., CALANTONE, R., "A critical look at technological innovation typology and innovativeness terminology: a literature review", The Journal of Product Innovation Management, 19 , p. 110-132, 2002.

OECD. Oslo Manual. Paris, 1992. Available at http:// www.oecd.org. Accessed in October 2003.

PETROFLEX, Petroflex's internal report, 2004

Silveira, G. - "Innovation diffusion: research agenda for developing economies", Technovation, 21, p. 767-773, 2001.

Utterback, J. M. - Mastering the dynamics of innovation, Harvard Business School Press, Boston, 1994.

Artigo elaborado por Paulo Luiz de Andrade Coutinho, R\&D Coordinator - Petroflex Indústria e Comércio S.A.; J. V. Bomtempo e Adelaide Antunes, Professores - Escola de Química, Universidade Federal do Rio de Janeiro, RJ. 